\title{
Risk Assessment and Risk Perception of Coronary Heart Disease in Gaza Strip, Palastine
}

\author{
Hatem Dabbak ${ }^{1}$, Mostafa A. Arafa ${ }^{2 *}$ \\ ${ }^{1}$ University College of Ability Development-Gaza, Palestine Red Crescent Society \\ ${ }^{2}$ Uro-Oncology Research Chair, College of Medicine, King Saud University, Riyadh, KSA \\ Email: " mostafaarafa@hotmail.com
}

Received 19 September 2014; revised 4 November 2014; accepted 20 November 2014

Copyright (C) 2014 by authors and Scientific Research Publishing Inc.

This work is licensed under the Creative Commons Attribution International License (CC BY).

http://creativecommons.org/licenses/by/4.0/

c) (i) Open Access

\section{Abstract}

Aim: The aim of the present study was to estimate the prevalence of coronary heart diseases (CHD) risk factors among Ghaza (Palastine) university students, to assess the CHD risk among them using a suitable scoring system and to identify how they perceive their risk of CHD. Methods: During the period from May 2008 to May 2009, 501 students were involved. Participants were subjected to the following activities; self administered questionnaire: including socio-demographic data, medical history of chronic diseases, family history about CHD, knowledge and perception of risk factors, anthropometric measurements in addition to laboratory testing. Results: The mean age was $20.8 \pm 2.07$ years; $54 \%$ were females. The prevalence of hypertension and DM was $3.6 \%$ and $0.4 \%$ while it was $2.6 \%$ for hypercholesterolemia. The mean levels of LDL-C (88 mg/dl vs $85.5 \mathrm{mg} / \mathrm{dl})$ and HDL-C (52.4 mg/dl vs $42.6 \mathrm{mg} / \mathrm{dl})$ were higher among females than among males. Smoking was more prevalent among males than among females $(33.1 \%$ vs $1.7 \%)$ with a total prevalence of $19 \%$. Overweight and obesity were more prevalent among males $(30.7 \%$ vs $22.5 \%$ and $9.6 \%$ vs $5.6 \%$ ). In contrast to risk perception female students tend to be more knowledgeable than males with regards to different aspects of CHD. The overall level of perceived risk was moderate. Logistic regression analysis revealed that age and sex were associated significantly by higher level of total perception $(p<0.05)$. Conclusion: Health education and health promotion programs should be implemented and integrated within the primary health care sectors and directed to university students before admission. Further research needed to be implemented on larger sample to test knowledge and perception of the public in regard to their risk for heart disease including school children and community so that education could be provided in a more focused manner.

\footnotetext{
"Corresponding author.
} 
Keywords

Coronary Heart Diseases (CHD)

\section{Introduction}

Although the prevention and treatment of coronary heart diseases (CHD) have received increased attention, CHD remains the leading cause of death and major cause of morbidity in developed and developing countries [1]. CHD is emerging as a major public health problem in the EMR, where the proportion of deaths from CHD ranges from $25 \%$ to $45 \%$ [2].

Risk assessment is defined as "a systematic approach to estimating the burden of disease and injury due to different risk" [3]. Use of risk prediction charts to estimate total cardiovascular risk is a major advance on the older practice of identifying and treating individual risk factors, such as raised blood pressure and raised blood cholesterol.

Risk perception is the subjective assessment of the probability of a specified type of accident happening and how much we are concerned with the consequences. Perceiving risk includes evaluations of the probability as well as the consequences of a negative outcome [4]. Perceiving a health threat is the most obvious prerequisite for the motivation to change risk behaviors. If one is not aware of the risky nature of one's actions, motivation for change cannot emerge [5]. Risk perception affects health behavior and emotional well-being among individuals facing a health threat.

Perception of CHD risk appears to be positively correlated with a desire to make risk-reducing behavioral changes and with actual behavioral change. Perceptions of personal risk occupy a central role in theories of individual health behavior such as the health belief model (HBM), which suggests that perceptions of risk play a critical role in a patient's compliance with recommended health behaviors [6].

Knowledge of risk factors and positive perception of CHD risk in younger age group is the corner stone for building effective community preventive measures and evaluation of community needs. In Palestine, weak or no national data are available on the overall incidence and prevalence of cardiovascular and other non-communicable disease. The Ministry of Health depends on mortality data to estimate the impact of these diseases. There is a gradient with increasing morbidity and mortality of coronary heart disease (CHD) in Palestine. The study arose from a genuine interest in assessing CHD risk, health beliefs, knowledge and practices of this community as a fundamental concern felt for the health of this population.

The aims of the current work were to estimate the prevalence of CHD's risk factors among university students, to assess the CHD risk among university students, by using a suitable scoring system and to assess students' knowledge, and perception of CHD risk by using the health belief model.

\section{Methods}

The study was carried out in the main three universities in Gaza Strip (Al-Azhar University, The Islamic University of Gaza, and Al Aqsa University) through a cross sectional approach. The target population comprised the second and third year regular university students to avoid attrition by students' failure and dismiss in the first year, and to avoid loss of follow up after graduation in the fourth year.

\subsection{Sampling}

Based on the prevalence of diabetes mellitus (6.4\%) as a risk factor for CHD [7], the required sample size was 575, with 95\% confidence level, 90\% test power, and 0.02 absolute precision was 575 students. Subjects were proportionally allocated based on the number of students in each university and then selected randomly. The selection took into consideration the types of colleges, and year of education in each university. Six hundred subjects were chosen to avoid attrition and maintain high response rate and divided as follow (240 from the Islamic University of Gaza, 180 from Al-Azhar University, and 180 from Al-Aqsa University).

\subsection{Data Collection Tools}

1) A self administered questionnaire was used to collect the data concerning the following: socio-demo- 
graphic, medical and family history of hypertension, diabetes mellitus (DM), dyslipidemia, and their medical and non-medical management, family history of CHD and premature death, smoking habit, and physical activity by using NCD-surveillance tool-kit questionnaire ${ }^{(303)}$. For physical activity: participants were classified as physically active if they practice any leisure time physical activity (LTPA).

Assessment of students' knowledge

Seven questions were designed to assess the students' knowledge related to CHD, i.e. signs and symptoms of CHD, onset of disease, different risk factors, complications, measures to reduce risk, at what age screening of CHD should begin The total knowledge score ranged from 0 - 12 points, it was graded into three levels: Good: 10 - 12 points (>75\%), Fair: 6 - 9 points (50\% - 75\%), and Poor level: $<6$ points $(<50 \%)$.

Assessment of students' risk perception

Three questions were designed to assess the students' level of perceived susceptibility to CHD (three point scale). The total score ranged from 3 - 9 points and graded as high level of perceived susceptibility 8 - 9 points ( $>75 \%$ ), moderate level 5 - 7 points ( $50 \%$ - 75\%), and low level $\leq 4$ points $(<50 \%)$.

Perceived seriousness of the disease, perceived benefits of risk factors modification and perceived barriers to intention to life style changes were assessed using different Likert scales. Five items (three points scale) was used for the first one with a total score ranged from 3 - 15 and ten items (three points scale) for the second with a total score ranged from 10 - 30. Both were graded as high level (>75\%), moderate level $(50 \%-75 \%)$ and low level of perception $(<50 \%)$. Concerning perception of barrier to life style changes, three questions were used for assessment a score of 3 denotes identification of two or more barriers, 2 denotes presence of only one barrier, and 1 indicates that there is no barriers for each question, total score was obtained by summing the scores for the 3 questions, it was ranged from 3 - 9 points and classified as the previous ones; high, moderate and low level of perceived barrier. The total score of risk perception ranged from 20 - 63 points and was classified as the following:

- High level of perceived risk $\geq 46$ (>75\%)

- Moderate level of perceived risk 31 - 45 (50\% - 75\%)

- Low level of perceived risk $\leq 30(<50 \%)$

2) Physical measurements

Blood pressure and body mass index (BMI) was calculated directly by the standard formula: weight (kg)/ height $\mathrm{m}^{2}$.

3) Laboratory investigations

Morning fasting blood specimens were collected between 8 and 10am and analyzed for serum total cholesterol (TC), high-density lipoprotein (HDL-c), and triglyceride (TG), and fasting blood glucose, while low-density lipoprotein (LDL-c) was calculated by using the formula $\{\mathrm{LDL}-\mathrm{c}=\mathrm{TC}-(\mathrm{HDL}-\mathrm{c}+\mathrm{TG} / 5)\}$, serum LDL-c was assessed by separation of LDL-c and determination of cholesterol bounds to these fractions. All results were reported in $\mathrm{mg} / \mathrm{dl}$ using whole numbers.

\subsection{Ethical Consideration}

An official letter of approval to conduct the study was obtained from the Helsinki Committee (Ethical Research Committee in Gaza Strip), each participant was given a letter to set forth the objectives and benefits from the study and stress upon confidentiality of information. A consent from was signed by each participant.

\subsection{Data Management}

A pilot study was conducted for testing the reliability of the questionnaires, and different tools. Chronbacks alpha ranged from 0.66 to 0.84 for different tools.

Scoring of risk assessment computed on SPSS using the same scale of Framingham Global Risk Score [8]. Data was expressed in the form of means and standard deviations, Chi-square test were used for analysis of categorical data, t-test was used for comparing of continuous. P value for statistical significant between groups was $\leq 0.05$ with $95 \%$ confidence interval, multiple linear regression for predicting factors that affect total perception where the dependant variable was percentage change in risk perception while the independent variables were age and total knowledge score (as quantitative variables), educational level, sex, medical history, family history of CHD, family history of PMD (as dummy variables). 


\section{Results}

A total of 501 students completed the survey questionnaire, the response rate was $87 \%$, while it was $72 \%$ (361 out of 501) among those who gave blood sample for laboratory analysis. Framingham risk score formula was applied only for 361 participants, while all participants were included in the result analysis.

About 54\% of the participants in the survey were males. Their age ranged from 19 - 40 years, mean age 20.8 \pm 2.07 years. Six percent of the participants were married and the percentage was higher among female students.

\subsection{Prevalence of Risk Factors}

Table 1 shows the reported history of different risk factors to CHD, only $3.6 \%$ of the study population reported that they have elevated blood pressure. It was slightly more prevalent among female students (4.3\% vs 3\%) without a statistical significant difference. The prevalence of diabetes is much lower, where $99.6 \%$ of the study subjects were free from DM and it was 100\% negative among female participants. By examination, the fasting blood sugar level was above normal in three subjects. Only 2.6\% of the students reported history of hypercholesterolemia. The mean total cholesterol and LDL-cholesterol levels among the study subjects were $151.4 \mathrm{mg} / \mathrm{dl}$, $86.8 \mathrm{mg} / \mathrm{dl}$ respectively. It was higher among females than males (156.6 mg/dl vs $146.8 \mathrm{mg} / \mathrm{dl})$ and it was statistically significant, while there was no statistical significant difference for the LDL-C means (88 mg/dl vs 85.5 $\mathrm{mg} / \mathrm{dl})$. Ninety five percent of the participants had desirable total blood cholesterol, and normal LDL-C levels, while only about $5 \%$ had borderline high to high total cholesterol, LDL-C and triglycerides levels. With regards to triglycerides levels; males tend to have higher triglycerides levels than female participants (18.2\% vs 4.1\%).

Tobacco smoking was encountered in $19 \%$ of the study population $(n=95)$, which was more prevalent among male students in comparison to females (33\% vs 1.7\%). Family history of CHD was reported by $14.2 \%$ of the students. According to WHO classification of body mass index (BMI), overweight ( $\left.\geq 25-29.9 \mathrm{Kg} / \mathrm{m}^{2}\right)$, and obesity $\left(\mathrm{BMI} \geq 30 \mathrm{Kg} / \mathrm{m}^{2}\right.$ ) were more significantly prevalent among male versus female participants, where about $8 \%$ were obese and $27 \%$ were classified as overweight. Those who were practicing LTPA comprised $60.7 \%$ of the study population, yet the difference between both sexes was not statistically significant.

Based on reported history it was observed that $14.8 \%$ of the students reported the presence of two or more risk factors and the percent was more statistically significant in males $(p=0.001)$, Table 2 . On the other hand, and based on laboratory testing of the lipid profile and FBS, blood pressure measurement, and BMI calculation, more than half (51.3\%) of the participants had no risk factors, $37.3 \%$ had only one risk factor, and $11.4 \%$ had two and more risk factors. Risk factors were significantly more identified among male students rather than among female students ( $\mathrm{p}<0.001)$, Table 3 .

\subsection{Risk Score Calculation (Assessment) Based on Framingham Risk Scoring System}

Risk assessment for determining 10-year risk for developing CHD events, was carried out by using the Framingham risk score updated for NCEP guidelines. The risk factors included in the Framingham calculation of 10-year risk were: age, total cholesterol, HDL cholesterol, smoking status, and systolic blood pressure. The risk score classified the estimated risk of CHD into three categories; low risk with total score less than $10 \%$, moderate risk with a total risk score range from $\geq 10 \%-20 \%$, and the high risk category of $\geq 20 \%$ risk score. Table 4 shows that all the study population were placed in low risk score category (less than $10 \%$ ).

\subsection{Knowledge about Coronary Heart Disease}

Nearly 32\% of the studied sample stated that they don't know any of the risk factors. The most identified risk factors for CHD were smoking (47\%), obesity (42.3\%), high blood cholesterol (38.5\%), high blood pressure (31.5\%), genetics and physical inactivity 25\% for each, stress (24\%), and advanced age(21)\%. With exception to smoking and advanced age, females tend to be more knowledgeable of obesity, high BP, high cholesterol, and stress as risk factors for CHD. More than half (52\%) of the participants mentioned that they don't know any of the signs and symptoms of CHD. The most common risk reducing methods of CHD identified by the study participants were cessation of smoking (50\%), practicing LTPA (49.3\%), maintain ideal weight (41.1\%), avoidance of psychological stress (26.5\%), control of blood sugar level in diabetic patients (21.4\%), and about one fifth mentioned blood pressure control in hypertensive patients. Concerning different aspects of knowledge; risk factors, signs and symptoms, risk reduction strategies, complications, in addition to the total CHD knowledge mean 
Table 1. Distribution of the studied sample according to reported history of different risk factors.

\begin{tabular}{|c|c|c|c|c|c|c|c|}
\hline \multirow{2}{*}{ History of Hypertension } & \multicolumn{2}{|c|}{ Male } & \multicolumn{2}{|c|}{ Female } & \multicolumn{2}{|c|}{ Total } & \multirow{2}{*}{ p Value } \\
\hline & $N=270$ & $\%$ & $N=231$ & $\%$ & $\mathrm{~N}=501$ & $\%$ & \\
\hline Yes & 8 & 3.0 & 10 & 4.3 & 18 & 3.6 & 0.475 (NS) \\
\hline \multicolumn{7}{|l|}{ History of DM } & \multirow{2}{*}{0.19 (NS) } \\
\hline yes & 2 & 0.7 & 00 & 00 & 2 & 0.4 & \\
\hline \multicolumn{7}{|l|}{ History of Hypercholesterolemia } & \multirow{2}{*}{0.997 (NS) } \\
\hline YES & 7 & 2.6 & 6 & 2.6 & 13 & 2.6 & \\
\hline \multicolumn{8}{|l|}{ Smoking Behavior } \\
\hline Current & 91 & 33.1 & 4 & 1.7 & 95 & 19.0 & \multirow{3}{*}{0.001} \\
\hline Ex-smoker & 21 & 7.8 & 3 & 1.3 & 24 & 4.8 & \\
\hline Never & 158 & 58.5 & 224 & 97.0 & 382 & 76.2 & \\
\hline \multicolumn{7}{|l|}{ Family History of CHD } & \multirow{2}{*}{0.850 (NS) } \\
\hline Yes & 39 & 14.4 & 32 & 13.9 & 71 & 14.2 & \\
\hline \multicolumn{8}{|l|}{ BMI Kg/m $\mathbf{m}^{2}$} \\
\hline Underweight $<18.5$ & 12 & 4.4 & 13 & 5.6 & 25 & 5.0 & \multirow{4}{*}{0.036} \\
\hline Normal weight 18.5 - 24.9 & 149 & 55.2 & 153 & 66.2 & 302 & 60.3 & \\
\hline Overweight $\geq 25-29.9$ & 83 & 30.7 & 52 & 22.5 & 135 & 26.9 & \\
\hline Obese $\geq 30$ & 26 & 9.6 & 13 & 5.6 & 39 & 7.8 & \\
\hline \multicolumn{7}{|l|}{ Practicing LTPA } & \multirow{2}{*}{0.272 (NS) } \\
\hline Yes & 170 & 63 & 134 & 58 & 304 & 60.7 & \\
\hline
\end{tabular}

Only positive answers (yes) were reported in the table. NS: non significant.

Table 2. Prevalence of risk factors among subjects based on history.

\begin{tabular}{ccccccccc}
\hline \multirow{2}{*}{ No. of Risk Factors } & Male & \multicolumn{3}{c}{ Female } & \multicolumn{3}{c}{ Total } & p Value \\
& $\mathbf{N =} \mathbf{2 7 0}$ & $\mathbf{( \% )}$ & $\mathbf{N = 2 3 1}$ & $\mathbf{( \% )}$ & $\mathbf{N = 5 0 1}$ & $\mathbf{( \% )}$ & \\
\hline No risk factors & 105 & 38.9 & 111 & 48.1 & 216 & 43.1 & $<0.001$ \\
Only one risk factor & 107 & 39.6 & 104 & 45.0 & 211 & 42.1 & 14.8 & \\
$\geq 2$ risk factors & 058 & 21.5 & 016 & 06.9 & 074 & &
\end{tabular}

Table 3. Prevalence of risk factors among subjects based on examination.

\begin{tabular}{ccccccccc}
\hline No. of Risk Factors & Male & \multicolumn{3}{c}{ Female } & \multicolumn{2}{c}{ Total } & p Value \\
& $\mathbf{N}=\mathbf{2 7 0}$ & $\mathbf{( \% )}$ & $\mathbf{N = 2 3 1}$ & $\mathbf{( \% )}$ & $\mathbf{N = 5 0 1}$ & $\mathbf{( \% )}$ & \\
No risk factors & 108 & 40.0 & 149 & 64.5 & 257 & 51.3 & \\
Only one risk factor & 121 & 44.8 & 066 & 28.6 & 187 & 37.3 & $<0.001^{*}$ \\
$\geq 2$ risk factors & 041 & 09.6 & 016 & 05.2 & 057 & 11.4 & \\
\hline
\end{tabular}

Table 4. Distribution of the studied sample by the estimated 10-year percentage of risk of CHD.

\begin{tabular}{|c|c|c|c|c|c|c|}
\hline \multirow{2}{*}{ Score \% } & \multicolumn{2}{|c|}{ Male } & \multicolumn{2}{|c|}{ Female } & \multicolumn{2}{|c|}{ Total } \\
\hline & $N=192$ & $\%$ & $\mathrm{~N}=169$ & $\%$ & $\mathbf{N}=361$ & $\%$ \\
\hline$<1$ & 147 & 76.6 & 168 & 99.4 & 315 & 87.2 \\
\hline 1 & 32 & 16.7 & & & 32 & 8.9 \\
\hline 2 & 8 & 4.2 & & & 8 & 2.2 \\
\hline 3 & 2 & 1.0 & 1 & 0.6 & 3 & 0.8 \\
\hline 4 & 2 & 1.0 & & & 2 & 0.6 \\
\hline 6 & 1 & 0.5 & & & 1 & 0.3 \\
\hline
\end{tabular}


score, females were more statistically knowledgeable than males $(9.9 \%$ vs $8.3 \%, \mathrm{p}=0.001)$. Those who had good level of knowledge constituted $21.2 \%$ of the sample, while those with poor level comprised more than one half of the sample (51.9\%), Table 5.

\subsection{Risk Perception and Health Belief Model}

Risk perception (perceived susceptibility, seriousness, benefit, and barriers)

Table 6 shows the distribution of the studied sample according to the perceived susceptibility to CHD. While majority of the students (72.5\%) expected the development of CHD, only 8.2\% perceived themselves as more exposed to CHD risk than other colleagues. The difference between both sexes was statistically significant.

The distribution of the studied sample according to the perceived seriousness (severity) to the CHD is presented in Table 7; where more than ninety percent (91\%) perceived themselves as anxious of becoming exposed to the disease, only $3.6 \%$ of the participants perceived CHD as very serious, and $43 \%$ perceived it as serious to some extent. Nearly $7 \%$ of the sample perceived CHD as disturbing to work and activity of daily living (ADL). Most of them (83.4\%) didn't perceive it as a public health problem.

\subsection{Perceived Benefit of Complying with CHD Preventive Measures}

Less than $2 \%$ of the studied sample agreed to the benefit of stop smoking, and practicing LTPA as CHD risk reduction methods. Nearly similar percentage (2.6\%, and $2.4 \%)$ agreed to that "eating fat free diet and increase vegetables intake" and "avoidance of stress" reduce the risk of developing CHD. Less than four percent (3.4\%) agreed that ideal body weight and avoidance of obesity reduce the risk of CHD occurrence. Also nearly similar percentage (4.2\%, and $4 \%$ ) agreed to that regular measurement of blood pressure and blood glucose level is essential to prevent the development CHD. It is worth mentioning that a considerable percentage of our population ranged from $65 \%$ - 80\% didn't perceive any benefits of the previous measure for CHD risk reduction.

Perceived barriers of lifestyle changes in areas of smoking, dietary habits and practicing LTPA

With regards to stop smoking; the most commonly perceived barriers were social and cultural strain (44.2\%), study pressure (24.2\%), all friends are smoking (23\%), type of strong tolerance (22\%), and it needs will power (21\%). There was a statistically significant difference between males and females participants. $24 \%$ of the participants perceived no barriers. Concerning eating healthy diet; the mostly commonly perceived barriers were increased cost (21\%), prefer quick meals (19.4\%), don't mind for increased weight, don't know healthy diet (10.6\% and $9.6 \%$ respectively). $44 \%$ of the study population were reported that they had no barriers to take healthy diet. 23\% of the students perceived no barriers to practicing LTPA. While barriers like no desire, having no time, having no suitable place, and having no decency represented $31.5 \%, 30.5 \%$, 20.6\% and $11.7 \%$ respectively. No statistically significant difference between male and female participants was detected regarding diet and LTPA.

Table 5 demonstrates the distribution of the studied sample according to the score of perceived susceptibility to CHD, perceived seriousness (severity), perceived benefit of complying with CHD preventive measures and perceived barriers of lifestyle changes where the perception of one fifth of the participants towards CHD was high. Only 3.6\% perceived CHD as highly serious disease, on the other hand the majority (81.8\%) expressed low perception of risk reduction methods to the development of the disease, very small percentage (1.4\%) perceived barriers toward the prevention of coronary heart disease as a high measure. The overall level of perceived risk was moderate among both male and female participants and the mean score showed a predominance of males over females.

The results of multiple regression revealed that out of seven factors included in the model, both sex (female) and age were found to have a significant impact on the total perception score. These variables accounted for $18 \%$ of the variability in change of perception score, Table 8.

\section{Discussion}

The prevention of CHD traditionally relies on the control of risk factors and positive perception of such factors among individuals as a major element of any strategy. Despite the benefits from risk reduction, lack of adherence is a fundamental problem in risk modification efforts in individuals at high risk or with CHD [9] [10].

CHD risk factors that are prevalent among the studied sample are concomitant to those identified by different 
Table 5. Mean and total scores of risk perception among the studied sample.

\begin{tabular}{|c|c|c|c|c|c|c|c|}
\hline \multirow{2}{*}{ Score } & \multicolumn{2}{|c|}{ Male } & \multicolumn{2}{|c|}{ Female } & \multicolumn{2}{|c|}{ Total } & \multirow{2}{*}{ p Value } \\
\hline & $N=270$ & (\%) & $\mathbf{N}=231$ & $(\%)$ & $\mathbf{N}=501$ & $(\%)$ & \\
\hline \multicolumn{8}{|c|}{ Perceived susceptibility } \\
\hline High & 68 & 25.2 & 36 & 15.6 & 104 & 20.7 & \\
\hline Moderate & 189 & 70 & 183 & 79.3 & 372 & 74.3 & $0.030^{*}$ \\
\hline Low & 13 & 4.8 & 12 & 5.2 & 25 & 5 & \\
\hline Mean (SD) & \multicolumn{2}{|c|}{$5.8(1.4)$} & \multicolumn{2}{|c|}{5.7 (1.29) } & \multicolumn{2}{|c|}{$5.77(1.38)$} & \\
\hline \multicolumn{8}{|c|}{ Perceived seriousness } \\
\hline High & 12 & 4.4 & 6 & 2.6 & 18 & 3.6 & \\
\hline Moderate & 177 & 65.6 & 140 & 60.6 & 317 & 63.3 & 0.183 (NS) \\
\hline Low & 81 & 30 & 85 & 36.8 & 166 & 33.1 & \\
\hline Mean (SD) & \multicolumn{2}{|c|}{$8.4(1.7)$} & \multicolumn{2}{|c|}{$8.1(1.6)$} & \multicolumn{2}{|c|}{$8.27(1.7)$} & \\
\hline \multicolumn{8}{|c|}{ Perceived benefit } \\
\hline High & 1 & 0.4 & - & - & 1 & 0.2 & \\
\hline Moderate & 71 & 26.3 & 19 & 8.2 & 90 & 18.0 & $<0.001^{*}$ \\
\hline Low & 198 & 73.3 & 212 & 91.8 & 410 & 81.8 & \\
\hline Mean (SD) & \multicolumn{2}{|c|}{$13.7(2.69)$} & \multicolumn{2}{|c|}{$12.75(2.05)$} & \multicolumn{2}{|c|}{$13.3(2.47)$} & \\
\hline \multicolumn{8}{|c|}{ Perceived barriers } \\
\hline High & 7 & 2.6 & - & - & 7 & 1.4 & \\
\hline Moderate & 157 & 58.1 & 107 & 46.3 & 264 & 52.7 & $0.001^{*}$ \\
\hline Low & 106 & 39.3 & 124 & 53.7 & 230 & 45.9 & \\
\hline Mean (SD) & \multicolumn{2}{|c|}{$5.03(1.1)$} & \multicolumn{2}{|c|}{$4.5(0.72)$} & \multicolumn{2}{|c|}{$4.8(0.98)$} & \\
\hline \multicolumn{8}{|c|}{ Total perception score } \\
\hline High & 1 & 0.4 & - & - & 1 & 0.2 & \\
\hline Moderate & 199 & 73.7 & 126 & 54.5 & 325 & 64.9 & $0.001^{*}$ \\
\hline Low & 70 & 25.9 & 105 & 45.5 & 175 & 34.9 & \\
\hline Mean (SD) & \multicolumn{2}{|c|}{$33.8(3.96)$} & \multicolumn{2}{|c|}{$31.1(3.2)$} & \multicolumn{2}{|c|}{$32.1(3.7)$} & \\
\hline \multicolumn{8}{|c|}{ Total knowledge score } \\
\hline Good & 46 & 17 & 60 & 26 & 106 & 21.2 & \\
\hline Fair & 73 & 27 & 62 & 26.8 & 135 & 26.9 & \\
\hline Poor & 151 & 56 & 109 & 47.2 & 260 & 51.9 & \\
\hline Mean (SD) & \multicolumn{2}{|c|}{$8.3(6.7)$} & \multicolumn{2}{|c|}{$9.9(7.5)$} & \multicolumn{2}{|c|}{$9.06(7.16)$} & 0.011 \\
\hline
\end{tabular}

NS = statistically not significant. "Statistically significant $\mathrm{p}<0.05$.

Table 6. Distribution of the studied sample according by their perceived susceptibility to CHD (Gaza 2008/09).

\begin{tabular}{|c|c|c|c|c|c|}
\hline \multicolumn{2}{|c|}{ Perceived Susceptibility Variables } & $\begin{array}{l}\text { Male } \\
\text { N (\%) }\end{array}$ & $\begin{array}{c}\text { Female } \\
\text { N (\%) }\end{array}$ & $\begin{array}{l}\text { Total } \\
\text { N (\%) }\end{array}$ & p Value \\
\hline \multirow{4}{*}{$\begin{array}{l}\text { Compared to a same age } \\
\text { colleague, what is the } \\
\text { probability of MI } \\
\text { occurrence after } 10 \text { years }\end{array}$} & Exposed more than him & $28(10.4)$ & $13(5.6)$ & $41(8.2)$ & \multirow{4}{*}{0.022} \\
\hline & Same possibility & $52(19.3)$ & $31(13.4)$ & $83(16.6)$ & \\
\hline & Exposed less than him & $36(13.3)$ & $26(11.3)$ & $62(12.4)$ & \\
\hline & There is no possibility & $154(57)$ & $161(69.7)$ & 315 (62.9) & \\
\hline \multirow{3}{*}{$\begin{array}{c}\text { Self evaluation for CHD } \\
\text { development }\end{array}$} & May occur & $189(70)$ & $174(75.3)$ & $363(72.5)$ & \multirow{3}{*}{0.368 (NS) } \\
\hline & Many not occur & $46(17)$ & $30(13)$ & $76(15.2)$ & \\
\hline & Don’t know & $35(13)$ & 27 (11.7) & $62(12.4)$ & \\
\hline
\end{tabular}

NS = statistically not significant. 
Table 7. Distribution of the studied sample according to their perceived severity (seriousness) of CHD.

\begin{tabular}{|c|c|c|c|c|c|}
\hline \multicolumn{2}{|c|}{ Perceived Severity Variables } & $\begin{array}{l}\text { Male } \\
\text { N (\%) }\end{array}$ & $\begin{array}{l}\text { Female } \\
\text { N (\%) }\end{array}$ & $\begin{array}{l}\text { Total } \\
\text { N (\%) }\end{array}$ & p Value \\
\hline \multirow{3}{*}{ CHD is considered as } & V. serious & $11(4.1)$ & $7(3)$ & $18(3.6)$ & \multirow{3}{*}{0.801 (NS) } \\
\hline & Serious to some extent & $116(43)$ & $98(42.4)$ & $214(42.7)$ & \\
\hline & Not serious & $143(53)$ & $126(54.5)$ & $269(53.7)$ & \\
\hline \multirow{3}{*}{$\begin{array}{l}\text { Anxiety from exposure } \\
\text { to CHD }\end{array}$} & V. anxious & $141(52.2)$ & 113 (48.9) & $254(50.7)$ & \multirow{3}{*}{0.076} \\
\hline & Sometimes become anxious & 112 (41.5) & 90 (39) & $202(40.3)$ & \\
\hline & No need to become anxious & $17(6.3)$ & $28(12.1)$ & $45(9)$ & \\
\hline \multirow{3}{*}{$\begin{array}{l}\text { How does the disease } \\
\text { affect daily life }\end{array}$} & Disturb work and ADL & $24(8.9)$ & $10(4.3)$ & $34(6.8)$ & \multirow{3}{*}{$0.048^{*}$} \\
\hline & Sometimes disturb ADL & 89 (48.6) & $94(51.4)$ & $183(36.5)$ & \\
\hline & Does not disturb ADL & $157(55.3)$ & $127(55)$ & $284(56.7)$ & \\
\hline \multirow{3}{*}{$\begin{array}{l}\text { Do you perceive CHD } \\
\text { as a public health } \\
\text { problem }\end{array}$} & Yes & $22(8.1)$ & $19(8.2)$ & $41(8.2)$ & \multirow{3}{*}{0.367 (NS) } \\
\hline & No & $27(10)$ & $15(6.5)$ & $42(8.4)$ & \\
\hline & Don’t know & $221(81.9)$ & $197(85.3)$ & $418(83.4)$ & \\
\hline \multirow{4}{*}{$\begin{array}{l}\text { Proportional mortality } \\
\text { from CHD to the total } \\
\text { mortality }\end{array}$} & High & $41(15.2)$ & $15(6.1)$ & $56(11.2)$ & \multirow{4}{*}{0.005} \\
\hline & Moderate & $143(53)$ & $122(46)$ & $256(52.9)$ & \\
\hline & Low & 45 (16.7) & $58(25.1)$ & $103(20.6)$ & \\
\hline & Don’t know & $41(15.2)$ & $36(15.6)$ & 77 (15.4) & \\
\hline
\end{tabular}

NS = statistically not significant.

Table 8. Multiple linear regression model for some predictors of percent of change in total perception score among participants.

\begin{tabular}{ccccc}
\hline Independent variables & B & (SE) & t & p-Value \\
\hline Constant & -4.96 & 20.96 & 0.237 & 0.818 \\
Educational level & 0.199 & 6.66 & 0.030 & 0.976 \\
Sex & 18.16 & 6.64 & 2.73 & 0.008 \\
Age & 1.89 & 0.941 & 2.011 & 0.048 \\
History of (DM, HTN, Hypercholestrolemia) & -8.57 & 11.09 & 0.99 & 0.325 \\
Family history of CHD & 12.27 & 12.39 & 0.99 & 0.325 \\
Family history of PMD & 2.90 & 6.909 & 0.390 & 0.697 \\
Pretest total knowledge & 0.354 & 0.459 & 0.77 & 0.444
\end{tabular}

$\mathrm{F}=2.617, \mathrm{p}=0.017, \mathrm{R}^{2}=0.181$

studies conducted in different countries [11]-[13]. Yet the association of these factors didn't vary by sex and it was more stronger in younger age group ( $<60$ years) [11].

The prevalence of the presence of $\geq 2$ risk factors and Just one factor in United States national estimate (2010) showed a marked difference in comparison to our reported results (17.9\% vs 14.8\%) and 37.3\% vs $42.1 \%$ respectively [13].

Smoking in the present study was less prevalent (19\%) in comparison with the studies conducted among Jordon University of Science and Technology students, 2008, (28.5\%) [14], Cairo University students, Egypt, 2003, (22\%) [15] and in Poland, 2007; among Public Health students at Medical University of Bialystok where it was 38.5\% [16]. In all studies the prevalence was significantly higher among male students. A cross-sectional study conducted at King Faisal University_Saudi Arabia (2010), showed that the overall narghile smoking was 12.6\% (8.6\% narghile only and 4.0\% both narghile and cigarettes) [17]. In general it was noticed that the prevalence of smoking among university students is varying from one country to another, but it is constantly higher among males. This marked higher prevalence of smoking among male Palestinian university students may be due to the 
unstable political conditions, cultural and social strains, uncontrolled tobacco sales, and finally the emerging of narghile as a social context to smoke.

The prevalence of overweight and obesity in the current study was higher and showed a significantly low percentage among female, in contrary to the results of Shahid Bahonar University of Kerman - Iran (2003) [18]. On the other hand, Amine and colleague at UAE University (1996); reported that the prevalence of overweight and obesity was higher among female than male students in $10.8 \%$, and $30.6 \%$ respectively [19]. Also the study conducted in University of Crete-Greece (2003), showed that $40 \%$ of male and $23 \%$ of female ( $3^{\text {rd }}$ year medical students) had a BMI $\geq 25.0 \mathrm{Kg} / \mathrm{m}^{2}$ [20]. In most reviewed studies; obesity was more prevalent among females. The relatively low prevalence of obesity among females in the current study could be ascribes to cultural and/or environmental factors in addition, more than half of female participants reported practicing LTPA as a weight reduction advice.

Concerning physical activity, the present study revealed that $39.3 \%$ of the participants were physically inactive or don't practice any LTPA. It is less prevalent than many studies conducted in the EMR which revealed that physical inactivity is a highly prevalent health-related problem in the region. A study conducted at Alexandria University-Egypt (2007), revealed that $33.5 \%$ of the students were physically inactive [10], while data available from a study conducted in Isfahan-Iran (1999), revealed that physical inactivity represented 53\% [21]. It has been known since the 1950s that people with higher levels of physical activity have a lower risk of CHD, and there is a consensus that the association is causal.

In general, female participants in the current study tend to be more knowledgeable than males, in contrast to risk perception where males perceived themselves to be at higher risk than females.

In accordance with a study conducted in Karachi-Pakistan, less than $20 \%$ of the participants were aware of the risk factors of CHD. The major CHD risk factors identified by participants were hypertension, high cholesterol, and smoking 12\% [9]. A survey conducted at Arizona State University (2004) to explore students' attitudes about heart disease risk and preventive strategies showed lower level of perception of heart disease risk for women than for men [22]. Results from a cross-sectional study conducted at University of Calabar, Nigeria (2007), revealed that the level of awareness of ischemic heart disease as a leading cause of death is poor even in an academic environment. Knowledge of risk factors is also poor and is influenced by the level of educational attainment. Life style modification strategies are still not widely accepted irrespective of educational status [23].

At Columbia University Medical Center (2005), a sub-study of 125 women with no known history of CVD participated in a clinical evaluation of CHD risk to assess perceived versus calculated risk of CHD using Framingham global risk assessment for calculating absolute 10 -year risk; $59 \%$ had a 10 -year risk of less than $10 \%$, however only half of these women accurately perceived their risk as low. After brief educational intervention, the women's ability to correctly categorized their personal CHD risk improved significantly [24].

The lower level of women's risk perceptions for heart disease in the current study is parallel to a common misperception found in a study conducted in the US (2005), which revealed that the general public still perceives heart disease as primarily a health problem for men. Evidence shows that women perceive breast cancer as a greater risk than CHD. These misperceptions may lead women to underestimate their risk for CHD and fail to seek early interventions to prevent unnecessary morbidity and mortality [25]. Women still continue to associate cardiovascular disease with obese, stressed men who smoke. Lack of accurate risk perception may prevent women from appreciating the need for early preventive behaviors, as well as the importance of seeking early lifesaving interventions in the presence of active CHD symptoms [26].

Age and sex were found to be the most significant predictors of risk perception in the current study. In 2010, the study conducted in Jordan revealed that older Jordanians had higher perception of risk of CHD, in addition; Jordanian women perceive CHD more as unobservable, unknown, new and delayed in manifestation of harm than Jordanian men [27]. Similarly, the results of a study conducted in USA (2006), showed that women did not practice health promotion behaviors (HPB) regularly and had low CHD knowledge levels, a high perception level of benefits, and a moderate level of perceived barriers to CHD risk modification. Backward multiple regression analysis demonstrated that smoking history, family history of CHD, CHD knowledge levels, and perceived barriers to CHD risk modification were the best predictors of HPB in women without CHD [28]. CHD was often perceived as a "male disease" and women tend to be unmentioned or "invisible" in discussion about heart disease, this belief in heart disease as a male problem persist among women in UK, and in all European countries [29].

In conclusion a person perception of a threat posed by a health problem is associated with actions aimed at 
reducing the threat. In addition, knowledge and awareness of risk factors are essential components of behavior change [30] [31]. The low perceived risk reduced the probability of individuals to seek either medical help for regular check up, or even change or modify their lifestyle as early detection of altered health status and as primary prevention method. Comprehensive risk-reduction counseling and health-promotion programs using lowcost policy and environmental interventions effectively support healthy lifestyles can have a great impact on heart disease and are likely to reduce individual's health and productivity-related cost.

\section{Limitation of the Study}

This study is not without its limitations. In the present study, there was a sole dependence on self-report measures to gather data. Also, the cross-sectional design disallows any allusion to causality. Students in such area are under stress for long time which may affect their perception of risk and alter their way of thinking to health issues. At last health belief model as a psychological model does not take other factors into consideration, such as environmental or economic factors that may influence health behaviors.

\section{Acknowledgements}

This work was funded by College of Medicine Research Centre, Deanship of scientific Research, King Saud University.

\section{References}

[1] World Health Organization (2008) Cardiovascular Disease: Prevention and Control. http://www.who.int/dietphysicalactivity/publications/facts/cv/en/.htm

[2] World Health Organization Statistical Information System (2006) Core Health Indicators World Health Statistics 2006. http://www.who.int/en/

[3] World Health Organization (2002) Reducing Risks, Promoting Healthy Life. World Health Report 2012, World Health Organization, Geneva.

[4] Sjoberg, L., Moen, B. and Rundmo, T. (2004) Explaining Risk Perception. An Evaluation of the Psychometric Paradigm in Risk Perception Research. Norwegian University of Science and Technology, C Rotunde Publikasjoner.

[5] Renner, B., Scupp, H., Vollman, M., Hartung, F., Schmalzle, R. and Panzer, M. (2008) Risk Perception, Risk Communication and Health Behavior Change. Zeitschrift für Gesundheitspsychologie, 3, 150-153. http://nbn-resolving.de/urn:nbn:de:bsz:352-opus-71352 http://dx.doi.org/10.1026/0943-8149.16.3.150

[6] Christian, A.M., Mochari, H.Y. and Mosca, L.J. (2005) Coronary Heart Disease in Ethnically Diverse Women: Risk Perception and Communication. Mayo Clinic Proceedings, 80, 1593-1599. http://dx.doi.org/10.4065/80.12.1593

[7] World Health Organization (2001) Health Conditions of, and Assistance to, the Arab Population in the Occupied Arab Territories, Including Palestine. WHO, Geneva.

[8] Framingham Heart Study (2008). http://www.nhlbi.nih.gov/about/framingham/index.html

[9] Dodani, S., Mistry, R., Farooqi, M., Khwaja, A. and Qureshi, R. (2004) Prevalence and Awareness of Risk Factors and Behaviors of Coronay Heart Disease in an Urban Population of Karachi, the Largest City of Pakistan: A Community Survey. Journal of Public Health, 26, 245-249. http://dx.doi.org/10.1093/pubmed/fdh154

[10] Abolfotouh, M.A., Bassiouni, F.A., Mounir, G.M. and Fayyad, R.Ch. (2007) Health-Related Lifestyles and Risk Behaviors among Students Living in Alexandria University Hostels. Eastern Mediterranean Health Journal, 13, 376-391.

[11] Anand, S.S., Islam, S., Rosengren, A., Franzosi, G., Dteyn, K., Yusufali, A.H., Keltai, M., Diaz, R., Rangarajan, S. and Yusuf, S. (2008) Risk Factors for Myocardial Infarction in Women and Men: Insights from the INTERHEART Study. European Heart Journal, 29, 932-940. http://dx.doi.org/10.1093/eurheartj/ehn018

[12] Cooper, R.S., Ordunez, P., Ferrer, M.D.F., Munoz, J.L.B. and Brito, A.E. (2006) Cardiovascular Disease and Associated Risk Factors in Cuba: Prospects for Prevention and Control. American Journal of Public Health, 96, 94-101. http://dx.doi.org/10.2105/AJPH.2004.051417

[13] Kulina, E.V., Yoon, P.W. and Keenan, N.L. (2010) Prevalence of Coronary Heart Disease Risk Factors and Screening of High Cholesterol Level among Young Adults, United States, 1999-2006. Annals of Family Medicine, 8, 327-333. http://dx.doi.org/10.1370/afm.1137

[14] Khader, Y.S. and Alsadi, A.A. (2008) Smoking Habits among University Students in Jordon: Prevalence and Associated Factors. Eastern Mediterranean Health Journal, 14, 897-904. 
[15] Nassar, H. (2003) The Economics of Tobacco in Egypt: A New Analysis of Demand. Health, Nutrition and Population Discussion Paper, International Bank for Reconstruction and Development/World Bank, Washington DC.

[16] Kanicka, M., Szpak, A., Drygas, W., Rzeznicki, A. and Kowalska, A. (2007) The Prevalence of Tobacco Smoking among Public Health Students at Medical University of Bialystok. Advances in Medical Sciences, 52, 60-63.

[17] Taha, A.Z., Sabra, A.A., Al-Mustafa, Z.Z., Al-Awami, H.R., Al-Khalaf, M.A. and Al-Momen, M.M. (2010) Water Pipe (Shisha) Smoking among Male Students of Medical College in the Eastern Region of Saudi Arabia. Annals of Saudi Medicine, 30, 222-226. http://dx.doi.org/10.4103/0256-4947.62838

[18] Shahbazpour, N. (2003) Prevalence of Overweight and Obesity and Their Relation to Hypertension in Adult Male Students in Kerman-Iran. International Journal of Endocrinology and Metabolism, 2, 55-60.

[19] Amine, E.K. and Samy, M. (1996) Obesity among Female University Students in United Arab Emirates. The Journal of the Royal Society for the Prevention of Health, 116, 91-96. http://dx.doi.org/10.1177/146642409611600206

[20] Bersias, G., Mammas, I., Linardakis, M. and Kafatos, A. (2003) Overweight and Obesity in Relation to Cardiovascular Disease Risk Factors among Medical Students in Crete, Greece. BMC Public Health, 3, 3-8. http://dx.doi.org/10.1186/1471-2458-3-3

[21] Sarraf-Zadegan, N., Boshtam, M. and Rafiei, M. (1999) Risk Factors for Coronary Artery Disease in Isfahan, Iran. European Journal of Public Health, 1, 20-26. http://dx.doi.org/10.1093/eurpub/9.1.20

[22] Collins, K.H., Dantico, M., Shearer, N. and Mossman, K. (2004) Heart Disease Awareness among College Students. Journal of Community Health, 29, 405-420. http://dx.doi.org/10.1023/B:JOHE.0000038655.19448.b2

[23] Ansa, V.O., Oyo-Ita, A. and Essien, O.E. (2007) Perception of Ischemic Heart Disease, Knowledge of and Attitudes to Reduction of Its Risk Factors. East African Medical Journal, 84, 318-323.

[24] Christian, A.H., Mochari, H.Y. and Mosca, L.J. (2005) Coronary Heart Disease in Ethnically Diverse Women: Risk Perception and Risk Communication. Mayo Clinic Proceedings, 80, 1593-1599. http://dx.doi.org/10.4065/80.12.1593

[25] Hart, P.L. (2005) Women’s Perceptions of Coronary Heart Disease: An Integrative Review. Journal of Cardiovascular Nursing, 20, 170-176. http://dx.doi.org/10.1097/00005082-200505000-00008

[26] Vanchecke, T.E., Miller, W.M., Franklin, B.A., Weber, J.E. and McCullough, P.A. (2006) Awareness, Knowledge, and Perception of Heart Disease among Adolescents. European Journal of Cardiovascular Prevention \& Rehabilitation, 13, 718-723. http://dx.doi.org/10.1097/01.hjr.0000214611.91490.5e

[27] Ammouri, A.A., Neubager, G., Mrygan, M.I. and Hamaideh, S.H. (2011) Perception of Risk of Coronary Heart Disease among Jordanians. Journal of Clinical Nursing, 20, 197-203. http://dx.doi.org/10.1111/j.1365-2702.2010.03192.x

[28] Thanavaro, J.L., Moore, S.M., Anthony, M., Narsavage, G. and Deliacath, T. (2006) Predictors of Health Promotion Behavior in Women without Prior History of Coronary Heart Disease. Applied Nursing Research, 19, 149-155. http://dx.doi.org/10.1016/j.apnr.2005.07.006

[29] Macintyre, S., McKay, L. and Ellaway, A. (2005) Who Is More Likely to Experience Common Disorders: Men, Women, or Both Equally? Lay Perceptions in the West of Scotland. International Journal of Epidemiology, 34, 461466. http://dx.doi.org/10.1093/ije/dyh333

[30] Pender, N.J., Murdaugh, C.L. and Parsons, M.A. (2002) Health Promotion in Nursing Practice. 4th Edition, Prentice Hall, Julie Alexander.

[31] Maston-Koffman, D., Goetzel, R.Z., Anwari, V.V., Shore, K.K., Orenstein, D. and LaPier, T. (2005) Heart Healthy and Stroke Free: Success Full Business Strategies to Prevent Cardiovascular Disease. American Journal of Preventive Medicine, 29, 113-121. 
Scientific Research Publishing (SCIRP) is one of the largest Open Access journal publishers. It is currently publishing more than 200 open access, online, peer-reviewed journals covering a wide range of academic disciplines. SCIRP serves the worldwide academic communities and contributes to the progress and application of science with its publication.

Other selected journals from SCIRP are listed as below. Submit your manuscript to us via either submit@scirp.org or Online Submission Portal.
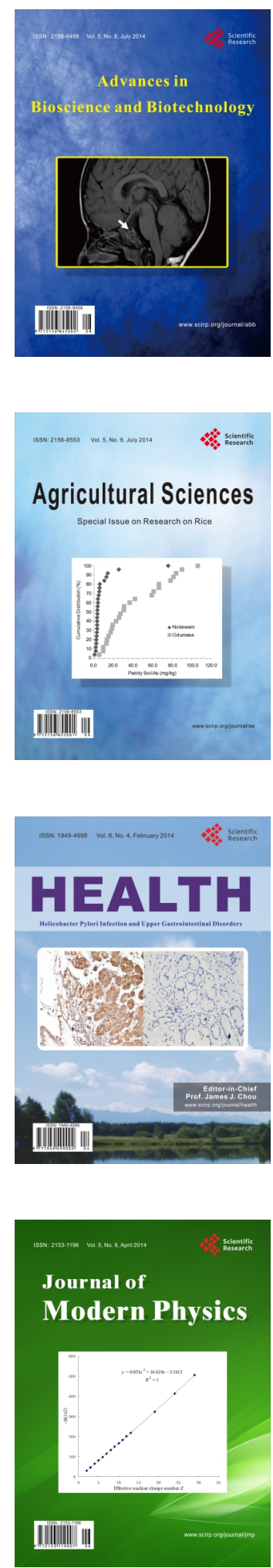
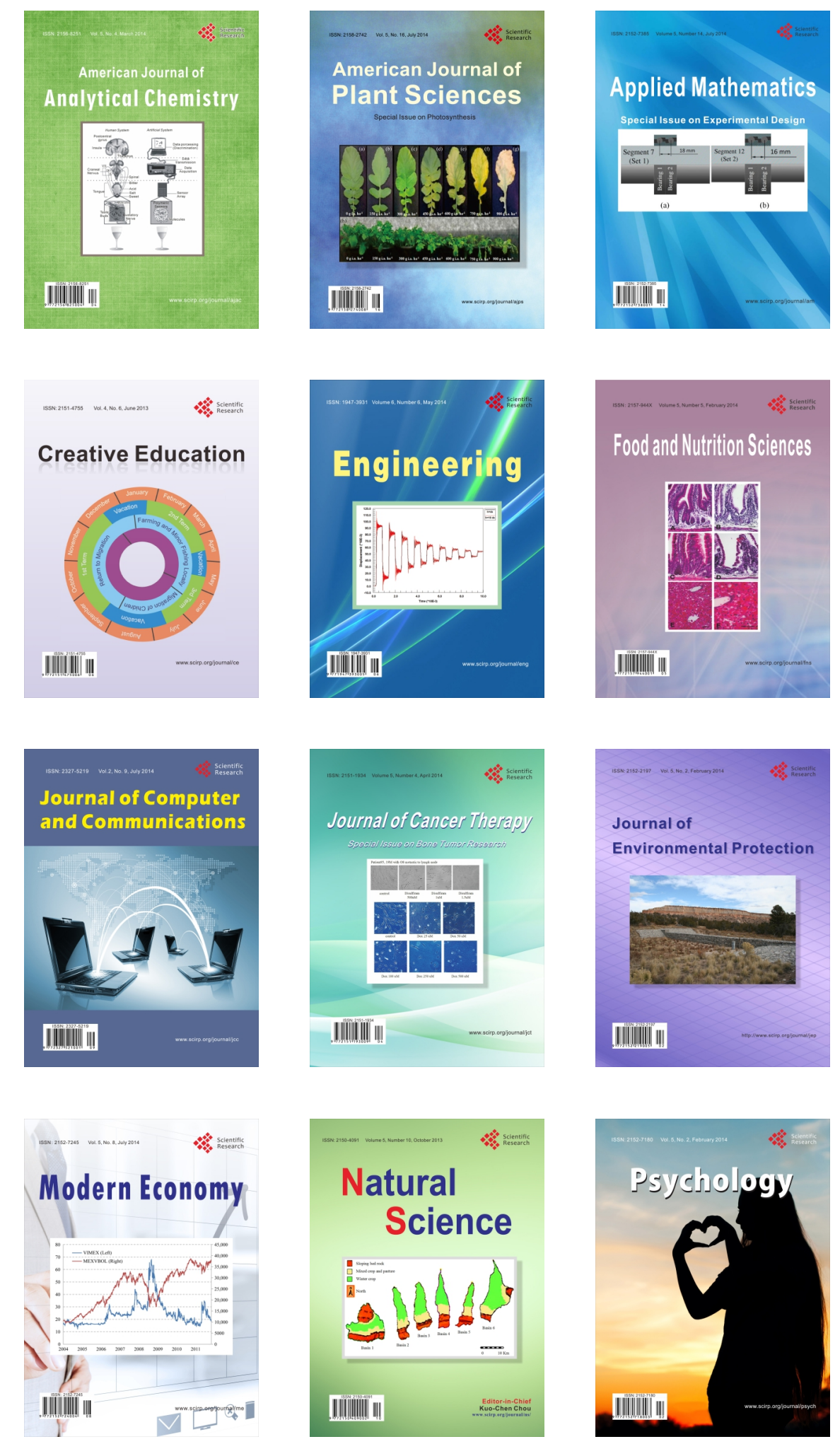